\title{
El movimiento campesino en El Salvador: evolución y lucha
}

\author{
Alfonso Goitia \\ Emesto Galdámez
}

\section{Introducción}

El movimiento campesino en El Salvador se ha desarrollado con mayor fuerza en los últimos 25 años. Aqui se trata de analizar y estudiar las características de su desenvolvimiento, sus luchas fundamentales y sus formas de articulación al movimiento popular en su conjunto. Es importante considerar que el pals durante estos años ha vivido una de sus etapas más convulsivas a nivel político y social, grandes transformaciones se han presentado y se siguen desarrollando. En este contexto el movimiento campesino ha sido uno de los agentes fundamentales del cambio y tiene nuevos retos que enfrentar en el marco de la reconstrucción y la consolidación de la paz.

1. Algunos antecedentes fundamentales: el movimiento campesino durante la década de los años 70 .

1.1. La Federación Cristiana de Campesinos Salvadoreños (FECCAS) y la Unión de Trabajadores del Campo (UTC).

Cualquier intento por comprender la evolución del Movimiento Campesino en El Salvador durante el último cuarto de siglo, sería

- Trabajo presentado al Proyecto: Movimientos Rurales y democracia en Amé. rica Central en los Noventa. Desarrollado por la Coordinadora Regional de Investigaciones Económicas y Sociales (CPIES) y el Transnational Institute (TNI) de Holanda. 
sumamente parcial si pretendiese pasar por alto, la obligada referencia a la Federación Cristiana de Campesinos Salvadoreños (FECCAS) y a la Unión de Trabajadores del Campo (UTC). Y esto es así porque ambas organizaciones preconizaron lo que más tarde serian, a largo plazo, la pautas de desarrollo del movimiento campesino. Por una parte enunciaron la tendencia hacia la integración de unidades organizativas cada vez mayores y más complejas de múltiples entidades campesinas. Por otra parte anticiparon que, dadas las constantes históricas de la desequilibrada distribución de la propiedad de los recursos económicos del pais y de la represión institucionalizada del Estado, la única via para avanzar en sus luchas reivindicativas o en su accionar politico era construyendo alianzas estratégicas con otras organizaciones populares.

Fue a mediados de los años sesenta cuando empezaron a darse las primeras manifestaciones de organización campesina. En el mes de junio de 1965 se celebró el primer congreso campesino, el cual es ubicado cronológicamente como el momento de gestación de FECCAS'. Desde un principio esta organización se fue planteando como principales líneas de acción reivindicativa, la libre sindicalización de los Irabajadores del campo, la necesidad de llevar a cabo un amplio programa de reforma agraria, la mejora de los salarios pagados en el campo y la conveniencia de aglutinar en una sola unidad al movimiento de los trabajadores ${ }^{2}$. Posteriormente, gracias a la participación de la Universidad Nacional ${ }^{3}$, se facilitó el surgimiento de la UTC. Aún y cuando en sus inicios estas organizaciones tuvieron derroteros independientes, su diario contacto con las bases campesinas, la similitud de las prácticas políticas observadas, la coincidencia de los objetivos perseguidos, la conciencia de trabajar con y para los mismos sectores populares, la afinidad ideológica de sus plataformas de luchas, las terminaron conduciendo a crear la Federación de Trabajadores del Campo (FTC)4. Esta serla el bastión por medio del cual el movimiento campesino empezaría a decantar como una fuerza social revolucionaria de corte popular.

Desde el principio la organización se perfiló como una entidad sumamente combativa, con un carácter eminentemente contestario. Sus bases eran campesinos que, a través del contacto con las prédicas de la Iglesia de los pobres ${ }^{5}$, habian venido cobrando conciencia de la causas de su sufrimiento y de la necesidad ineludible de organizarse para cambiar el estado de cosas vigentes en la sociedad salvadoreña, a pesar de que lal proceder significara desaliar el ordenamiento jurldico laboral que exclula el derecho del campesino a asociarse en sindicatos ${ }^{\theta}$. La influencia de esas enseñanzas cristianas se reflejaban principalmente en la lectura hecha y en la explicación dada a la realidad del campo. De 
alguna u otra forma en sus planteamientos socio-económicos, siempre recurrlan y retomaban el concepto de violencia institucionalizada, según el cual ésta "Consiste (...) en una situación estructural de injusticia por la que la mayoría del pais se ve privada de lo necesario para vivir. Hay en nuestro pals una estructura socio-económica, respaldada por una estructura legal y protegida por una estructura política, que mantiene a la mayorla de los ciudadanos en límiles infrahumanos de subsistencia y de participación en los bienes sociales del pais, haciendo imposible que esas mayorias puedan disfrutar de sus derechos fundamentales. Más aún esa estructura impide con todas sus fuerzas que esas mayorías se organicen para defender sus derechos y sus justas aspiraciones"7. Esta valoración ético-religiosa era insertada en un esquema ideológico de inspiración maxista-leninista. En tal sentido planteaban que para superar esta situación de miseria habría que destruir el sistema capitalista-dependiente, a efectos de alcanzar la definitiva liberación ${ }^{8}$.

En esencia, la lucha reivindicativa emprendida originalmente por FECCAS-UTC giraba en torno a los problemas de acceso a la tierras y las condiciones precarias de trabajo prevalencientes en el agro. Sus formas de lucha consistían en la realización de movilizaciones, marchas de protesta y en la presentación de peticiones al gobierno para aumentar los salarios mínimos rurales, mejorar las condiciones de comida e higiene en haciendas y fincas, reducir la renta de la tierra, disminuir el precio de los insumos agricolas y bajar las tasas de interés aplicadas a los créditos. Estas demandas no encontraban eco alguno o, si lo encontraban, la respuesta institucional dada consistla en sofocar, mediante la violencia de los cuerpos de seguridad del Estado, toda manifestación de descontento y disconformidad campesina ${ }^{9}$. Paulatinamente esta situación política de democracia restringida, salvaguardada elicazmente por el aparato militar, aunada a un proceso creciente de activismo político militante, fue arrinconando a la organización a adoptar posiciones cada vez más radicales. Esto significó el ir aceptando sin cortapisas al marxismo como la única e indiscutible interpretación de la realidad social de la cual también dimanaba una línea de acción política y una forma especifica de organización ${ }^{10}$. Naturalmente el resultado de haber dado semejante paso conllevarla, de modo progresivo, a la organización a ir poniendo por delante de las demandas reivindicativas-laborales, las demandas contenidas en su proyecto político revolucionario.

\subsection{La incorporación de FECCAS-UTC al BPR}

A partir de julio de 1975, después del fraude las elecciones presiden- 
ciales de 1972 y la consiguiente negación de la vía del sufragio para acceder al poder por parte de la oposición, el binomio FECCAS-UTC abandonó formal y públicamenle lo que hasta entonces se habla mantenido como el pertil de un movimiento exclusivamente campesino. En esa fecha, con la participación concertada de otras siete organizaciones ${ }^{11}$ de diversa procedencia social y con distintos matices ideológicos, decidieron conformar el organismo de política unitaria popular ${ }^{12}$ llamado el Bloque Popular Revolucionario (BPA).

Ese acontecimiento marcó, a la postre, el inicio de toda una nueva etapa para el movimiento campesino como totalidad, independientemente de cual fuese la línea doctrinal de la agrupación que lo representara. Significó, ya más específicamente, que el movimiento campesino se enrrumbó desde entonces hacia el establecimiento de alianzas profundas y/o circunstanciales con otras fuerzas y sectores de la sociedad, a efectos de ganar mayor capacidad de imponer sus demandas gremiales y politicas.

La incorporación de FECCAS-UTC al B.P.R. se tradujo en el avance de las organizaciones revolucionarias de masas en pos de la unificación. Ahora FECCAS-UTC estabas adscritas a un órgano cuyos objetivos se hablan cifrado para la acción puramente política, pues se fundamental interés, aún y cuando levantara estandartes reivindicativos-laborales, era organizar, integrar y movilizar un sólo frente de lucha para la consecución de la revolución popular ${ }^{13}$. Para FECCAS-UTC su incorporación al B.P.R. significó sellar "una alianza estratégica con organizaciones consecuentes de otros sectores explotados y oprimidos de nuestro pueblo (obreros, pobladores de tugurios, maestros, estudiantes). Esta alianza está basada en principios nacidos de los intereses de la clase trabajadora, y con ella hemos venido dando los primeros pasos en el forjamiento de un frente revolucionario de masas que, fundándose en la alianza obrero-campesina con hegemonia proletaria, es la única garanlia de que un dia no muy lejano podremos terminar para siempre con este sistema de explotación e injusticia y construir una sociedad cimentada en la solidaridad, la igualdad, la colaboración y la paz"14.

Para algunos analistas políticos este paso significó el desbordamiento de la organización campesina, la pérdida de especificidad en la identificación de sus intereses concretos, la supeditación a una alianza genérica con otras fueras politicas donde lo que básicamente se compartla ${ }^{15}$ era la ideologla manxista-leninista, el ejercicio de una violencia revolucionaria no armada, las articulaciones orgánicas con agrupaciones político-militares clandestinas y el sueño de la construcción de una sociedad socialisla. A la larga toda esta gama de factores acarrearla 
efectos contraproducentes a la organización campesina. Sin embargo, hay quienes son de la opinión ${ }^{16}$ que únicamente en la alianza con otros grupos sociales, los campesinos organizados velan la posibilidad de triunfar ante el proyecto económico-político instaurado y defendido por el capital agrario, el gobierno y el ejército.

Los métodos de lucha empleados por el B.P.R., frente a la campaña de asesinatos, desaparecimientos, tortura, operativos militares, captura y persecución desatada por la Fuerza Armada en forma masiva y constante en contra de las organizaciones populares, también fueron escalando e sus niveles de violencia. Ahora ya no sólo se empleaban huelgas, movilizaciones, manifestaciones pacíficas, repartos de propagada, colocación de carteles y mantas con consignas revolucionarias. También se introdujeron innovadoras acciones políticas tales como movilizaciones combativas de pinta y quema de buses, toma de fábricas, embajadas y edilicios públicos, retención de representantes patronales, etc.

El periodo 1975/1979 fue caracterizado por un proceso de galopante polarización social. En la medida se fueron agravando las condiciones económicas y sociales, en la medida fue arreciando la intensidad de la represión militar contra todo grupo opositor al régimen, en la medida se fueron clausurando los canales de expresión de la voluntad popular, !a pujanza de las organizaciones revolucionarias de masas iba aumentando tanto en el grado como en el número de acciones de desobediencia civil. Ellas salieron y se tomaron la calle como substituto de la existencia de una arena politica.

\subsection{La conformidad de la Coordinadora Revolucionaria de Ma- sas (CRM)}

Frente a esa la incontenible de agitación y presión popular ejercida hegemónicamente por las organizaciones revolucionarias de masas, catalizada de manera importante por el fraude cometido en las elecciones presidenciales de 1977, se produjo la insurrección militar del 15 de octubre de 1979. Este golpe de Estado respondla, en última instancia, a un intento institucional por restituir el desvanecido consenso social, ofreciendo para ello un programa de gobierno basado en relormas económicas y apertura de espacios políticos para la oposición. En el fondo de tal movimiento se podia entrever un componente contrainsurgente ${ }^{17}$, auspiciado por los Estados Unidos, cuyo propósito era el de arrebatarle banderas o minarle la base social al proyecto revolucionario popular, sobre todo después de que éste se habla visto fortalecido como posibilidad de realidad con el triunfo de la revolución sandinista en Nicaragua. 
Esa fue, ciertamente, la lectura $\theta$ interpretación dada al golpe por las organizaciones de izquierda. Por esa razón, el 11 de enero de 1980, promovieron la conformación de un frente unido de masas denominado la Coordinadora Revolucionaria de Masas (C.R.M.), en cuyo seno se aglutinaron las organizaciones populares B.P.R., Frente de Acción Popular Unificada (FAPU) ${ }^{18}$ y las Ligas Populares ${ }^{n} 28$ de febrero (LP-28) ${ }^{10}$ y el partido polílico Unión Democrática Nacionalista (U.D.N.). Según sus propias declaraciones, este proceso se justificaba porque "Estando las condiciones objetivas del desarrollo de nuestra sociedad, maduras para el triunto de la revolución, la unidad del Movimiento Popular resulta ser un imperativo, una necesidad histórica y una condición para marchar en la ruta definitiva hasta la victoria del pueblo"20. Ciertamente las condiciones de desarrollo del movimiento popular estaban presentes, pero no existlan todavia las condiciones de unidad en el conjunto de la oposición para enfrentar las estrategias que los sectores oligárquicos, el ejército y la administración norteamericana diseñaban en ese momento para El Salvador.

De acuerdo a las estimaciones conservadoras del informe ${ }^{21}$ del Subsecretario de Estado para Asuntos Interamericanos presentado ante la Comisión de Relaciones Exteriores de la Cámara de Representantes de los Estados Unidos, se calculaba que el B.P.R. Tendría entre 60.000 y 80.000 miembros, el FAPU entre 8,000 y 15.000 , sin aportar cifra alguna sobre el número de militantes de las Ligas. En números redondos el estimado global de los miembros de la C.R.N. andaba en el rango entre los 75.000 y los 100.000 miembros. No obstante lo anterior, la C.R.M. en una demostración de su poder de convocatoria y de su capacidad de movilización, organizó para el 22 de enero de 1980 la mayor concentración popular de toda la historia de El Salvador. Puso en la calle una multitudinaria manifestación de entre 200.000 y 300.000 personas para conmemorar el levantamienlo campesino de 1932. Esla fue dispersada y reprimida brutalmente.

El auge cobrado por el movimiento revolucionario de masas atrajo sobre las organizaciones populares que lo integraban, una masiva $\theta$ indiscriminada campaña ${ }^{22}$ represiva gubernamental orientada a diezmar sistemática e intencionalmente las bases poblacionales de su militancia era como si enlre las organizaciones revolucionarias de masas y el Estado se hubiera trabado una ley de hierro en sus relaciones funcionales. Dentro de esla lógica, al aumentar aquellas el lono de sus demandas reivindicativas o consignas politicas, disminula el valor de la vida y el respeto a los derechos humanos de los mililantes y, por ende, se elevaban los niveles de represión por parte del Estado. Sin embargo, esta reacción adquirio, verdaderamenle, cuotas de genocidio en el campo 
debido a los masivos $\theta$ indiscriminado de su carácter. Bajo el pretexto de combatir la subversión, el terrorismo y el comunismo internacional, el régimen constituido por la Democracia Cristiana-Fuerza Armada puso en funcionamiento a partir de enero de 1980, el esquema de reformas económicas con represión con el cual se pensaba estar desbaratando la fuerza insurgente de los grupos guerrilleros. Así tenemos que, en el perlodo comprendido entre en el perlodo comprendido entre el 9 de junio y el 31 de diciembre de 1980, poco tiempo después de haberse promulgado los decretos $N^{2} 153$ "Ley Básica de la Reforma Agrarian ${ }^{\text {23 }}$ y № 207 "Ley para la Afectación y Traspaso de Tierras Agrícolas a favor de sus Cultivadores Directos ${ }^{247}$, fueron asesinados por motivos políticos 1,814 campesinos y destruidas 0 incendiadas 1,185 casas rurales ${ }^{25}$. La gran mayorla de estos campesinos asesinados fueron victimas de cruentos operativos militares montados por el ejército y los cuerpos de seguridad contra la población civil indefensa, en un afán de desmantelar y aniquilar todo vestigio de actividad política dentro de la población rural.

A finales de 1981 el accionar y la presencia de las organizaciones revolucionarias de masas hablan cedido su lugar en el escenario nacional a la abierta guerra civil. Estas desaparecieron prácticamente de la arena politica. $Y$ esto es razonable de entender si vemos que, por un lado, las organizaciones populares se encontraban con la presencia poIítico militar del Frente "Farabundo Martí para la Liberación Nacional" (FMLN); por el otro, se hallaban perseguidas por la violencia represiva del Estado y el cierre de todos los espacios democráticos. En medio de estas circunstancias, muchas de las bases campesinas optaron finalmente por huir de sus lugares de origen para salvar siquiera la vida, engrosando las listas de desplazados o refugiados; otros decididamente pasaron a las filas del FMLN en calidad de combatientes o acompañantes.

A modo de reflexión, para concluir este apartado cabe introducir aquella valoración ético-política planteada on el editorial de la revista ECA respecto a la cuestión de las masas vivida en El Salvador: "Los sucesos pasados en los diez últimos años muestran (...), que muchas organizaciones masas fueron devoradas por la vorágine política y politizante de otras organizaciones, quedando asi no sólo desvirtuadas, sino desaparecidas del todo. La raíz de ello no está en que quisieron ser más de lo que eran sino, en que, al buscar ser más, dejaron de ser más de lo que eran sino, en que, al buscar ser más, dejaron de ser lo que eran". ${ }^{26}$ Esta apreciación refleja en forma genérica la dinámica adquirida entre finales de la década de los 70 y principios de los ochenta por el movimiento popular. No obstante el movimiento campesino y otras orga- 
nizaciones populares trataron de mantener sus márgenes de especificidad planteando sus reivindicaciones propias, en un contexto sumamente adverso. Esto se reflejara en procesos de reconstitución del movimiento campesino en los siguientes años.

\section{El movimlento campesino en los ochenta}

\subsection{El surgimiento de la Unidad Popular Democrática (U.P.D.)}

Paralelamente al desarrollo experimentado por las organizaciones revolucionarias durante los años setenta, pero con un perfil de protagonismo relativamente mucho más bajo y más focalizado en lo gremial, se habla venido conformando otras organizaciones de extracción campesina de diferentes tendencias de pensamiento. Estas organizaciones, en conjunción con otras fuerzas sociales cuyo común denominador ideológico era su posición centrista dentro del espectro político, entraron paulatinamente en contacto para aglutinar importantes grupos organizados de trabajadores del campo y de la ciudad. Este acercamiento de las relaciones entre sindicatos, cooperativas, partidos politicos, federaciones, etc. culminó en la creación de una alianza de organismos sumamente heterogénea, de naturaleza intergremial, llamada la Unidad Popular Democrática (U.P.D.). En ella se reunieron importantes agrupaciones campesinas tales como la Unión Comunal Salvadoreña (U.C.S.), Asociación de Cooperativas Agropecuarias Integras (ACOPAI), la Asociación Salvadoreña de Trabajadores Agropecuarios (ASTA), Central Campesina Salvadoreña (C.C.S.), la Asociación Nacional Indígena Salvadoreña (ANIS), asi como también sindicatos de gremios, industrias y partidos políticos (ver cuadro № 1).

Cabe añadir que la UPD nació como organización con fuertes vinculaciones formaies y orgánicas con la AFL-CIO (American Federation Labor-Congress of Industrial Organization) y con el AID (Agencia Internacional para el Desarrollo ${ }^{27}$. En elio podemos inferir el manifiesto interés norteamericano en penetrar e influir preponderamente a través del uso de la palanca financiera, dentro de la línea ideológica del movimiento reivindicativo campesino. En forma parcial esta situación ayudaba a explicar el porqué la UPD se posicionó como una fuerza social moderada, cuya bandera política era su oposición a los métodos irracionales de lucha empleados por las extremas de derecha e izquierda, para resolver democráticamente los problemas estructurales del pais.

El 9 de septiembre de 1980 la UPD salió formalmente a la luz pública mediante la publación de un comunicado donde se anunciaba su crea- 


\section{CUADAO N 1}

\section{Declaración de principios y objetivos de la Unidad Poular Democrática}

\begin{tabular}{|c|c|c|c|c|}
\hline $\begin{array}{c}\text { ORGANIZACIONES } \\
\text { MIEMBROS } \\
\end{array}$ & PAINCIPIOS & POUTICAS & $\begin{array}{l}\text { DEMANDAS } \\
\text { SOCIALES }\end{array}$ & $\begin{array}{l}\text { DEMANDAS } \\
\text { ECONOMICAS }\end{array}$ \\
\hline 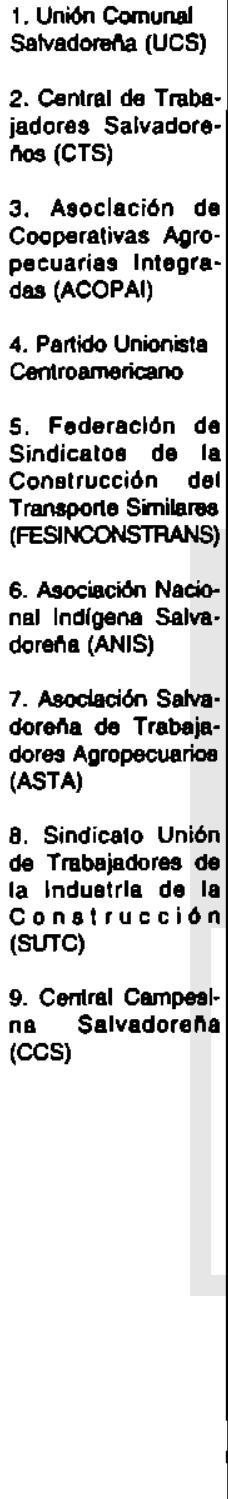 & 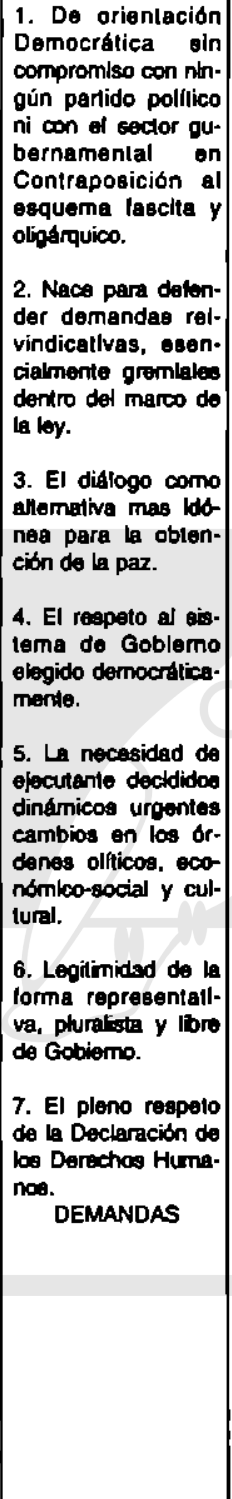 & 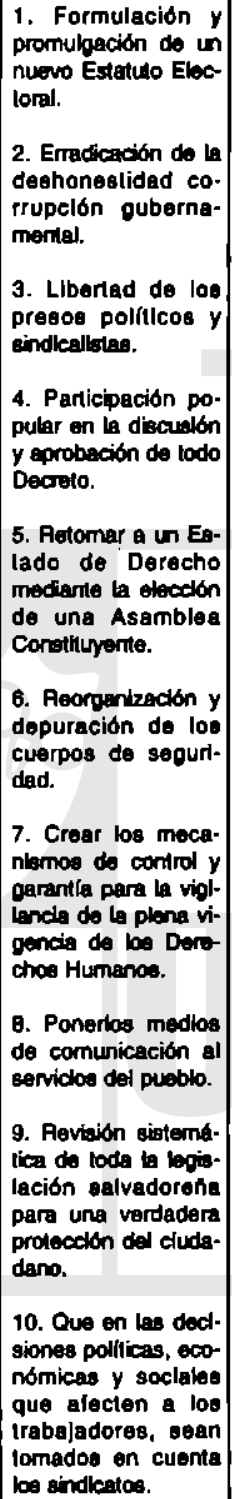 & 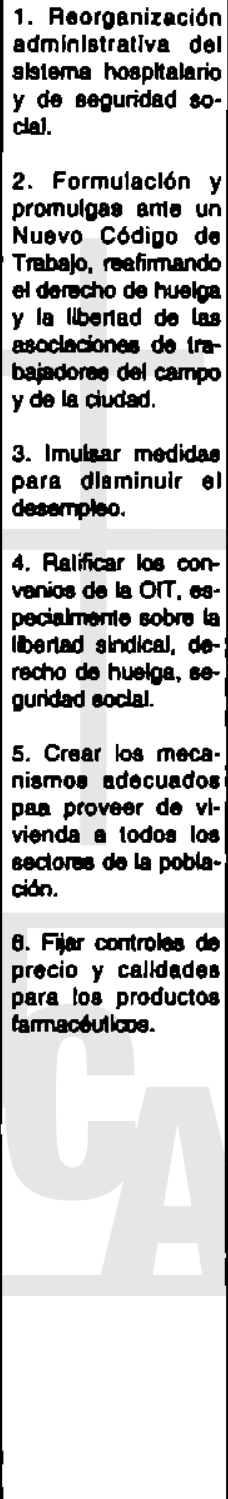 & 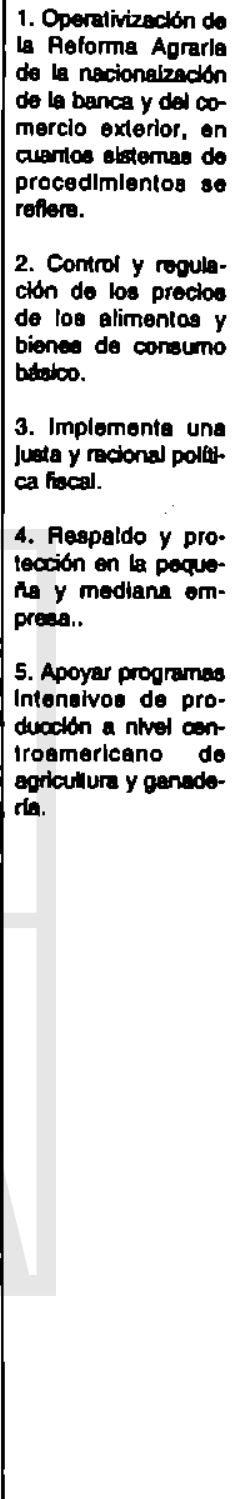 \\
\hline
\end{tabular}


ción, ası́ como también los principios, objelivos y demandas que originalmente marcarlan el norte de su lucha como fuerza social emergente dentro del turbulento contexto nacional. De entrada se definía a si misma como una organización de orientación democrática, carente de compromisos políticos con los partidos políticos o con el gobierno, nacida para defender demandas reivindicalivas de naturaleza gremial con apego a las normas jurídicas establecidas, partidaria de emprender urgentes cambios en los órdenes politico, económico y social (ver cuadro № 1).

Para algunos ese ideario era ya visto como una especie de alianza tácita, con el programa reformista de la $2 \mathrm{da}$. Junta Revolucionaria de Gobierno (2JRG). No obstante, desde el comienzo de su existencia, también la UPD abogaba por el diálogo como alternativa de una salida politica, no militar, a la crisis vivida por el pais. Más aún, la UPD se guardó de mantener distancia desde un principio con la 2JRG al plantear que al pueblo le asistirla el derecho de insurrección si ésta no respetaba su programa de apertura democrática, de cambios estructurales en la economia y no garantizaban los derechos constitucionales de los ciudadanos ${ }^{28}$.

Antes de proseguir con el análisis de la UPD vale la pena detenerse a fijar la atención en una de sus entidades miembro, la Unión Comunal Salvadoreña (U.C.S.). Ella representaba una vertiente muy significativa en el movimiento campesino salvadoreño y aportó el grueso de la base social de apoyo a la reforma agraria. Los orlgenes ${ }^{2 \theta}$ de la U.C.S. se remontan a la década de los años 60 cuando, el Instituto Americano para el Desarrollo del Sindicalismo Libre (I.A.D.S.L.), la Embajada de los Estados Unidos y la Agencia Internacional de Desarrollo (A.I.D.), apoyándose en el gobierno salvadoreño, se dieron a la tarea de desarrollar un movimiento sindical en el agro de orientación centrista. Fue hasta el año 1971 cuando la UCS obtuvo su personería jurldica, dándosele de esta manera el reconocimiento a la labor conjunta electuada por la IADSL, las distintas uniones comunales y las cooperativas, a pesar de que la sindicalización campesina de hecho seguia estando proscrita de las leyes de asociación permitidas por la Constitución. El gobierno vio en esta organización un instrumento a través del cual se podrian ir paliando las necesidades de crédito de avio, transterencias de tecnologia y de organización cooperativa.

En marzo de 1980, frente a la inminente urgencia de contar con el respaldo de una poderosa organización campesina no revolucionaria que apoyara el proceso de Relorma Agraria y ofreciera un cimiento social para el desarrollo de éste, el gobierno democristiano-militar, con la 
intermediación de la IADSL, entró en arreglos con la UCS para buscar la fórmula que llenara semejante vacio a cambio, ciertamente, de alguna cuota de poder ${ }^{30}$. La UCS aceptó. Al Secretario General de ésta se le concedió la presidencia del Instituto Salvadoreño de Transformación Agraria (ISTA). Desde sus planteles se coordinó con el personal de la UCS, la labor de difundir en las zonas rurales los alcances y el significado de tal reforma ${ }^{31}$. Pero, a pesar de ser la principal colaboradora de la 2JRG, la UCS tampoco pudo escapar a la violencia del proyecto autoritario reformista. Varios de sus promotores y afiliados, inclusive su Secretario General, cayeron victimas de los escuadrones paramilitares.

La UPD se cuidó, desde su creación, de jugar un papel de una moderada instancia critica a la 2JRG, denunciando con frecuencia la puesta en marcha de una reforma agraria con represión, exigiendo el cese de los impunes asesinatos de campesinos por parte del ejército, machacando la via de la no violencia como el camino idóneo para el establecimiento de un Estado de Derecho ${ }^{20}$. Otro punto sobre el que se volvió en numerosas ocasiones fue el planteamiento de que mientras no se resolviera el problema político del pais, era inútil estar pensando en reactivación económica.

Un factor que vino a cambiar fuertemente el panorama fue el lanzamiento de la primera gran ofensiva general por parte del FMLN, hito histórico con el cual se señaló el inicio formal de la guerra civil en EI Salvador. La 2JRG anuló de inmediato muchas de las libertades ciudadanas mediante el decreto $N^{2} 155$, con el cual se ponia en vigencia el Estado de Sitio. Este se prolongó ininterrumpidamente durante los siguientes 7 años. Lógicamente dicho suceso fue utilizado por el Gobiemo para desarticular los escasos espacios políticos y sociales, emprendiendo indiscriminadamente una represión nunca antes vista contra los movimientos laborales organizados, especialmente en el campo. Según las cirras ${ }^{33}$ publicadas por la oficina del Socorro Jurídico del Arzobispado de San Salvador, 3,665 campesinos fueron ejecutados por el ejército, los cuerpos de seguridad y los escuadrones paramilitares de la derecha, de enero a mayo del mismo año en cuestión. Ahora bien, a este respecto la UPD, aún y cuando mantuvo su apoyo ${ }^{34}$ al proceso de cambios y de reforma agraria, en sus posiciones públicas continuó martillando a la Fuerza Armada a cumplir con su Proclama del 15 de octubre en cuanto al cese de la extrema violencia, en cuanto a la restitución de las libertades públicas.

Posteriormente a las elecciones del 28 de marzo de 1982, las cuales fueron convocadas expresamente para elegir una Asamblea Constituyente y vistas por la UPD como un mecanismo ${ }^{35}$ genuino que podla 
ayudar a resolver los problemas de la clase trabajadora, se conformó un gobierno interpartidario de "Unidad Nacional", en cuya composición predominaron los representantes de los grupos económicos tradicionalmente hegemónicos. Naturalmente este cambio experimentado en la correlación de fuerzas al interior del Estado, fue percibido por la UPD como un inminente peligro para el proceso de cambios estructurales. Ello lo condujo a exigirle al nuevo gobierno la continuación y profundización de éstos, especialmente en cuanto a prorrogar el decreto 207 e implementar la $2^{4}$ etapa de la Reforma Agraria ${ }^{36}$. Las presiones para su logro fueron en crescendo, saliendo a la calle con manilestaciones y organizando inclusive movilizaciones campesinas para demandar el cumplimiento de sus peticiones. Llegaron al extremo de amenazar con desviar su conducla democrática si llegase a prevalecer la voluntad de los grupos que se oponen al cambio ${ }^{37}$. El decreto 207 se prolongó hasta 1983 , pero la $2^{9}$ etapa de la reforma agraria, que afectaría propiedades de 150 hectáreas y más, quedó aprisionada en el papel. La Constitución Política de 1983, fijó el límite de propiedad en 245 hectáreas y dio tiempo a los propietarios durante varios años a transierir sus excedentes de tierras.

Es interesante observar que las acciones arriba mencionadas hubieran sido prácticamente imposibles de realizar para cualquier otra organización popular que no contara con el visto bueno norteamericano y el apoyo de la Democracia Cristiana, considerando el Estado de Sitio imperante. Esta aparente libertad para organizarse y para protestar servia como prueba irrefutable ante la opinión pública mundial, del avance logrado en la apertura política y de la existencia de auténticos movimientos populares no radicalizados, a pesar de estarse viviendo en medio de la guerra civili3.

Tras haberse tomado "la decisión irrevocable de participar de una manera más activa y decisiva en la conformación de un nuevo gobierno"39 a mediados de 1983, la UPD renegó anticipadamente a su principio organizativo de no comprometerse con ningún partido político, a efectos de no ir cargando ningún complejo de culpa en las venideras elecciones presidenciales de 1984. A sabiendas de que el partido Demócrata Cristiano (PDC) carecia del respaldo social y politico necesario para levar al Ing. Duarte a Casa Presidencial, después de haberse desgastado en la 2JRG y debilitado sustancialmente su accionar en el gobierno de Unidad Nacional, la UPD estaba dispuesta a proporcionarle semejante apoyo requerido a cambio de la obtención de ciertas concesiones y de cuotas especificas de poder dentro del Ejecutivo. Esta negociación se concretizó con el sellamiento de una alianza proclamada 
como estratégica denominada "El Pacto Social". Entre los principales acuerdos escritos figuraban la búsqueda conjunta por alcanzar la pacificación nacional, la conformación de una sociedad democrática, pluralista, el compromiso de garantizar las relormas económicas y sociales iniciadas en 1980 y la concesión a los trabajadores organizados de representatividad en aquellos organismos públicos donde se deciden las políticas de gobierno que los afectan directamente ${ }^{40}$.

Según ciertos analistas ${ }^{4}$, la UPD sabla de antemano los costos que tendría que absorber al colaborar con un partido empeñado en hacer prevalecer un esquema de guerra contrainsurgente y represión. Sin embargo, también visualizaba que su participación como fuerza de contrapeso dentro del gobierno le permitirla estar permanentemente presionando por el diálogo nacional para alcanzar la paz, le facultarla seguir impulsando la continuación de las Reformas, asi como también le permitirfa salir beneficiada como organización al cristalizar operativamente muchas de las demandas contenidas en su plataforma organizativa. El triunfo de Duarte significó finalmente para la UPD el nombramiento de sus dirigentes en la presidencia del ISTA, en la subsecretaría del Ministerio de Agricultura y Ganaderla (MAG), la vicepresidencia del Banco de Fomento Agropecuario (BFA) y la Dirección de la Financiera Nacional de Tierras Agricolas (FINATA), siendo todas ellas entidades claves para la administración y seguimiento de la Reforma Agraria.

Una vez Duarte hubo salido electo presidente y la ayuda militar norteamericana fue aprobada por el Congreso, el valor del pacto social suscrito con la UPD empezó a depreciarse aceleradamente. En múltiples ocasiones esta organización del gobierno el cumplimiento de los compromisos adquiridos, principalmente en cuanto a adoptar medidas para mejorar las deterioradas condiciones de vida de los trabajadores, a propiciar el diálogo por la paz y a respetar el derecho a la vida de los ciudadanos $^{42}$. La Democracia Cristiana permaneció inmulable siguiendo el riel de la estrategia militar contrainsurgente de los ejércitos de Estados Unidos y El Salvador, aún y cuando ésta abriera ciertos espacios de expresión para la oposición organizada y el movimiento popular.

La participación obrero-campesina en el Gobierno Ejecutivo Demócrata Cristiano finalizó cuando este último implementó el plan económico de austeridad, el cual hacla recaer el mayor peso de financiar la guerra en los sectores populares. Este hecho obligó a la UPD a romper abiertamente con el pacto social en tanto, políticamente como organización de base popular, se vio en la encrucijada de optar preferencialmenle por un respaldo incondicional al gobierno o por privilegiar su solidaridad gremial 
en la lucha reivindicativa de sus intereses. Lógicamente esta segunda opción ea la única altemativa tenida para garantizar la continuidad de su existencia como organización.

\subsection{Aparición de la Unidad nacional de los Trabajadores Salvadore- ños (UNTS) y de la Unión Obrero Campesina (UNOC)}

Las evaluaciones de los impactos y benelicios de la reforma agraria, realizadas allá por 1985 , indicaban que la forma bajo la cual ésta se estaba implementando no sería capaz de resolver la ralz de problema de la injusta estructura de la tenencia de la tierra. Encima de eso, sus alcances habían sido recortados con la cancelación de la puesta en marcha de su II Etapa y de la derogatoria del acuerdo $N^{2} 207$. Se estimaba que, cinco años después de haberse iniciado el proyecto, 210 mil familias rurales segulan sin tener acceso a la tierra y el $60.6 \%$ de las familia campesinas se encontraban sumidas por debajo de la linea de la pobreza extrema. Estos datos apuntaban, obviamente, a la persistencia de una distribución concentrada de la propiedad y del ingreso en el agro.

El periodo comprendido entre 1986 y 1989 fue un perlodo durante el cual, catalizado y determinado por la misma dinámica de la guerra, en combinación con un franco deterioro de las condiciones objetivas de subsistencia para los sectores populares, se produjo un relanzamiento del movimiento campesino: Como rasgo distintivo más prominente podemos mencionar el cambio acelerado de su consciencia en cuanto a ya no volver a supeditar su autonomía a los proyectos de otras organizaciones cuyas estrategias de acción estuvieran centradas en torno a la lucha insurreccional o en la salida militar del conflicto. Se comprendió con un mayor grado de realismo politico, cuáles serán los límites de tolerancia para la disensión y la confrontación en el recién inaugurado ensayo liberal de apertura democrática, dentro de los cuales se podla maniobrar para propugnar por el cumplimiento de sus plataformas gremiales. Asimismo, este cambio de consciencia en cuestión se manifestó en los planteamientos reivindicativos de los campesinos. La solución de los grandes problemas nacionales se convirtió en una exigencia inherente a sus intereses fundamentales como fuerza social. De ahi en adelante, cada vez con un tono más elevado, el movimiento campesino fue demandando al gobierno la finalización de la guerra, el respeto a los derechos humanos, el cese de la represión y la construcción de la sociedad genuinamente democrática.

En segundo lugar, también durante este período en cuestión se perfi- 


\section{Cuadro Ne 2;}

Organizaciones mlembros y plataforma de la Unidad Naclonal de los Trabajadores Salvadoreños (UNTS)

\begin{tabular}{|c|c|c|}
\hline $\begin{array}{l}\text { Organizaciones } \\
\text { miembros }\end{array}$ & $\begin{array}{c}\text { Plataforma } \\
\text { en lo económlco }\end{array}$ & $\begin{array}{l}\text { Plataforma en } \\
\text { lo político }\end{array}$ \\
\hline $\begin{array}{l}\text { 1. Unidad Popular } \\
\text { Democrática } \\
\text { (UPD) } \\
\text { 2. Confederación } \\
\text { de Asociacio- } \\
\text { nes Cooperati- } \\
\text { vas de El Salva- } \\
\text { dor (COACES) } \\
\text { 3. Asociación Ge- } \\
\text { neral de Em- } \\
\text { pleados del Mi- } \\
\text { nisterio de Ha- } \\
\text { cienda } \\
\text { (AGEMHA) } \\
\text { 4. Central de Tra- } \\
\text { bajadores Sal- } \\
\text { va do re ñ o s } \\
\text { (CTS) } \\
\text { 5. Comité } 19 \text { de } \\
\text { Mayo. }\end{array}$ & $\begin{array}{l}\text { a) Derogar las medidas } \\
\text { del Programa de } \\
\text { Estabilización y } \\
\text { Reactivación Econó- } \\
\text { mica, especialmente } \\
\text { a los trabajadores a } \\
\text { traves de incremen- } \\
\text { tos en los precios de } \\
\text { los artlculos de con- } \\
\text { sumo popular, in- } \\
\text { sumos agricolas y } \\
\text { combustibles. } \\
\text { b) Decretar un aumento } \\
\text { de salarios para los } \\
\text { trabajadores del } \\
\text { campo y de la ciu- } \\
\text { dad en un porcenta- } \\
\text { je igual al incremento } \\
\text { del costo de la vida. } \\
\text { c) Que el gobiemo ga- } \\
\text { rantice la reapertura } \\
\text { o creación de luen- } \\
\text { tes de lrabajo a fin } \\
\text { de combatir el grave } \\
\text { problema del des- } \\
\text { empleo. } \\
\text { d) Ejecutar la II etapa } \\
\text { de la Reforma Agra- } \\
\text { ria y exonerar a las } \\
\text { cooperativas del } \\
\text { sector reformado del } \\
\text { pago de la deuda } \\
\text { agraria. }\end{array}$ & $\begin{array}{l}\text { a) Dar participación a } \\
\text { todos los sectores } \\
\text { organizados en el } \\
\text { gobiemo. } \\
\text { b) Garantizar el pleno } \\
\text { respeto a los dere- } \\
\text { chos humanos. } \\
\text { c) El diálogo entre los } \\
\text { actores en conflicto } \\
\text { como solución poll- } \\
\text { tica al problema de } \\
\text { la guerra. } \\
\text { d) Iniciar un proceso } \\
\text { de recuperación de } \\
\text { la soberanía y de } \\
\text { la independencia } \\
\text { patria, poniéndole } \\
\text { fin a la imposición } \\
\text { del gobierno de los } \\
\text { Estados Unidos. }\end{array}$ \\
\hline
\end{tabular}

Fuente: Comunicado "Propusla de la UNTS", tomado del Informativo Semanal "EI Salvador, PROCESO", año 6, № 226, 24 de febrero de 1986, San Salvador. 
la, de una manera mucho más definida, aquella tendencia profunda en la trayectorla del movimiento campesino a irse articulando orgánicamente en la conformación de poderosos órganos unitarios. En éstos se irán integrando sindicalos, cooperativas, asociaciones campesinas, centrales de obreros, organismos comunales y organizaciones de empleados públicos, agrupándose en un sólo cuerpo la variada gama de posturas ideológica. En esta unidad de lo diverso se pretende cohesionar políticamente la acción laboral en su carácter reivindicativo. Con este avance en el proceso de organización de los sectores populares, se producirá nuevamente un repunte en las actividades multitudinarias de masas con la celebración de pares, marchas y concentraciones públicas de protesta.

El 5 de febrero de 1986, como resultado inmediato de la "Asamblea Nacional por la Supervivencia de los Trabajadores ${ }^{n+43}$, se acordó en el pleno conformar la unidad nacional de los Trabajadores Salvadoreños (UNTS), con la participación inicial de la UPD, la Confederación de Asociaciones Cooperativas de El Salvador (COACES) y la Asociación General de Empleados del Ministerio de Hacienda (AGEMHA). Posteriomente se integraría a ella el Comité $1^{2}$ de Mayo, que aglutinaba a por lo menos 75 sindicatos, y la Central de Trabajadores Salvadoreños (CTS), la cual contaba con aproximadamente 40,000 miembros ${ }^{44}$. Además, en dicha Asamblea se acordó realizar una marcha el 21 de febrero, con la cual se demostraría más evidentemente el rechazo público al paquele de medidas económicas adoptado por el gobierno de Duarte, en enero de 1986, asi como también demostrar con hechos los esfuerzos organizativos llevados a cabo por estructurar un frente común de defensa de los intereses laborales ${ }^{45}$. En la marcha participaron entre 60,000 y 80,000 personas, y más de 150 organizaciones de 1rabajadores, constituyéndose en la mayor concentración popular habida en el país durante los últimos 5 años ${ }^{46}$. La mayoría de los manifestantes eran campesinos, prueba testimonial de la capacidad de movilización de COACES y otras organizaciones campesinas.

Los principales objetivos ${ }^{47}$ que la UNTS se propuso como orientadores de su lucha organizacional fueron los siguientes:

a) Elevar el nivel de vida de los trabajadores salvadoreños.

b) Contribuir a la instauración de la paz, apoyando los esfuerzos nacionales que deriven en un diálogo entre las partes en conflicto.

c) Luchar por la ejecución de un auténtica relorma agraria.

La plataforma formulada inicialmente por la UNTS (ver cuadro № 2) tenla dos grandes componentes. Por una parte serla reivindicativa por- 
que cuestionaba las banderas de la política económica aplicada por el gobierno, exigiendo de parte de este mejoras salariales, creación de fuentes de trabajo y la profundización de la reforma agraria. Pero igualmente era política al manifestar su oposición a la estrategia eminentemente militar promovida por la Democracia Cristiana, el ejército salvadoreño y por la administración Reagan, como solución del conflicto nacional. Debido a esta postura, a todas luces contrapuesta a los designios contrainsurgentes de tales actores, al UNTS fue desde un principio catalogada por el Gobierno y por. la Fuerza Armada con la viñeta estereolipada de "Fachada del Movimiento de Masas del FMLN". En consecuencia, todas sus acciones de protesta contra el régimen eran acusadas automáticamente de ser desestabilizadoras del orden social y la tranquilidad ciudadana, orquestada con las fuerzas subversivas. Naturalmente vista esta calificación dentro de la mentalidad militar, ello signiticaba que el ejército podia proceder con motivo justificado a la persecución, captura y represión ${ }^{48}$ tanto de los cuadros dirigentes como de sus bases militares, pues caían en la categoría de "enemigos de la patria".

El rompimiento de la alianza de la UPD con la Democracia Cristiana y el posterior surgimiento de la coaliación intergremial de amplio espectro UNTS, provocó alarma en el gobierno. Ello lo obligó a recurrir a los buenos oficios del IADSL, a efectos de contrarrestar la fuerza aglutinadora que podría desencadenar dicha organización en el sector labora|49. La estrategia a seguir sería la clásica maniobra de sembrar la confusión y provocar el divisionismo de las bases populares organizadas, urbanas y rurales, a fin de restablecer el equilibrio de fuerza concurrentes mediante la creación de un nuevo movimiento social cuyas bases no fuesen esencialmente de carácter antinorteamericano.

En conferencia de prensa realizada en dia 6 de marzo de 1986, a escasas 4 semanas de la formación de la UNTS, varios dirigentes gremiales anunciaron la constitución de la Unión Nacional obrero Campesina (UNOC). Como pilares fundamentales de la nueva organización aparecían la Confederación General de Trabajadores (CGT), y la Confederación de Trabajadores Democrático (CTD), las cuales mantenían nexos orgánicos muy relevantes con el Partido Demócrata Cristiano (PDC) y la IADSL ${ }^{50}$, respectivamente. A este intento del PDC de recomponer su base social también se sumaron varias federaciones de cooperativas de la Reforma Agraria (FESACORA, FECORASAL, FECORACEN), sectores disidentes de la UCS y ANIS, y organizaciones retiradas de la UPD tales como FESINCONSTRANS y CCS (ver cuadro No 3). Abiertamente la UNOC no desconoció su inspiración 
progubernamental al declarar que sus principales objetivos serian luchar por la autenticidad del proceso revolucionario democrático salvadoreño y apoyar la profundización de las reformas, según el proyecto y pensamiento original con que fueron creadas ${ }^{51}$. En otras palabras, ello se traducirla en la defensa de las relormas socio-económicas emprendidas por el gobiemo, contra cuyo desenvolvimiento se oponian por igual tanto la derecha totalitaria como la extrema izquierda.

Como primera medida de su poder de convocatoria real, la UNOC, realiz6 el 15 del mismo mes la llamada "Marcha por la Paz, las Reformas y la Democracia", a la cual concurrieron por lo menos $\mathbf{4 0 . 0 0 0}$ personas. El objetivo último de tal manifestación era darle un apoyo multitudinario a la gestión del PDC, demostrando su posicionamiento politico en a línea democrática-reformista. De este modo, la UNOC daba el primer paso para abrir un aparente centro político en el espectro ideológico de las organizaciones populares. Aduciendo su legitimidad como vanguardia de los trabajadores democráticos salvadoreños y su posición de tercera fuerza alternativa del pals, exhortaria en múltiples ocasiones "a toda la clase trabajadora salvadoreña para que, deponiendo actitudes de infantilismo extremista, nos decidamos de una vez por todas a luchar por nuestros verdaderos intereses y no de intereses de grupos políticos minoritarios que no representan la idiosincracia de la clase trabajadora, sino que pretenden manipularla para alcanzar la toma del poder... ${ }^{\text {52 }}$.

Sobre la base comparativa de sus respectivas plataformas se podia encontrar, en lo esencial, gran similitud en los planteamientos de la UNTS y de la UNOC. Ambas abogaban por la salida politica del conflicto por la vía del diálogo y la negociación. 'Igualmente, ambas denunciaban como origen de la guerra la situación de injusticia estructural en la distribución de la riqueza. Por ende, ambas avalaban el proceso de cambio y la profundización de la reforma agraria. También en las dos organizaciones denunciaban vehemente el irrespeto a los derechos humanos y el sufrimiento experimentado por los trabajadores de la represión militar, señalando la necesidad nacional de construir una sociedad libre y democrática. Sin embargo, la diferencia más relevante provenian del lado de la UNTS en cuanto a enjuiciar criticamente la incapacidad del gobierno de Duarte para atender las necesidades sociales y económicas de los trabajadores, exigiéndole con bastante frecuencia su renuncia como presidente $^{53}$. La UNOC, en cambio, mostraba su actitud progubernamental pidiendo condescendientemente la adopción de medidas económicas correctivas que mejoraran las condiciones de vida de los trabajadores. Asimismo, la UNTS, se dilerenciaba de la UNOC en su permanente 


\section{Cuadro № 3; \\ Organizaciones miembros y plataforma de la Unión Obrero Campesina (UNOC)}

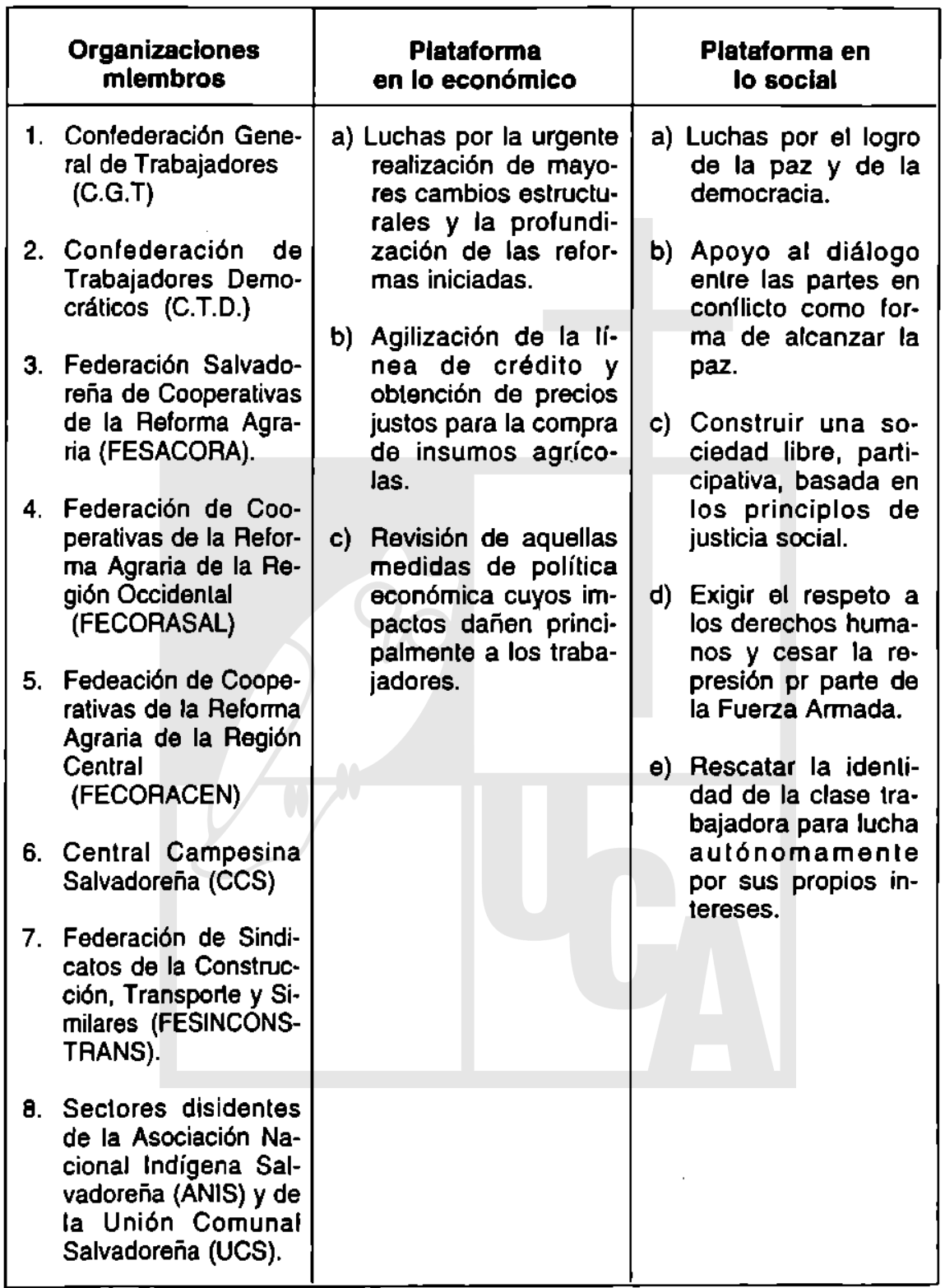


denuncia a la descarada intervención polltica y militar norteamericana en los asuntos internos del pais, responsable en última instancia de la continuación del proyecto de aniquilar a los sectores de oposición política y los grupos armados como fómula idónea para acabar con la guerra.

El 16 de noviembre de 1986, la UPD anunció públicamentes acerca de su irrevocable retiro de la UNTS, no dejando nada claras las verdaderas razones tomadas de base para tal decisión. En este retiro ambas organizaciones vieron debilitarse su base social debido a la decisión de ANIS y ANCA de no respetar la decisión adoptada en el congreso extraordinario de la UPD, y proseguir su participación en la UNTS. A la larga todo el movimiento descrito se traduciria en un importante recambio de la composición organizativa de dicha institución. El lugar ocupado por aquellas entidades gremiales de orientación relormista, cuya plataforma de lucha era predominantemente reivindicativa, pasó a ser suplantado por otros organismos tales como comités de derechos humanos, de familiares de desaparecidos, de desempleados, de estudiantes universitarios, etc. Ello transformó a la UNTS en una especie de Frente Político Populars, cuyas posiciones, opiniones y líneas de acción parecian coincidir o coordinarse con las organizaciones de masas del FMLN. Este proceso de politización y radicalización se aceleró enormemente durante 1987, durante el cual las acciones de la UNTS, se volvieron cada vez más disrruptivas del origen público, prevaleciendo en éstas las protestas violentas, sobre las manifestaciones políticas. Ahora bien, la anteposición de las demandas políticas a las puramente reivindicativolaborales produjo, al final de cuentas, la constilución de un grupo laboral muy combativo, pero con la gran desventaja de no poseer mayor capacidad de convocatoria en los sectores laborales.

A finales de los ochenta el movimiento campesino estaba inmerso en organizaciones que unificaban los intereses de los sectores populares en su conjunto. Esto no significaba que no desarrollaran especificamente su lucha reivindicativa en relación al acceso a la tierra, a la profundización de la reforma agraria, al acceso al crédito y salarios adecuados en el campo, entre otros. Pero el marco de la realidad nacional de una profunda crisis y la guerra subsumian las acciones que realizaban.

Otro de los aspectos importantes de esta década esta referido al proceso de organización campesina lograda a través de la relorma agraria. Ciertamente dicho proceso habla fortalecido la organización campesina, especialmente cooperativa. Para estos afios hablan surgido una gran cantidad de organizaciones cooperativas algunas como producto de su separación de la Federación Salvadoreña de Cooperativas 
de la reforma Agraria (FESACORA), instancia inicial creada en 1980, para impulsar el proceso de reforma agraria en su primera fase.

\section{El movimiento campesino en los noventa}

El período comprendido entre junio del 89 y los primeros años de los noventa, esta marcado por varios acontecimientos importantes que redefinen el proceso de desarrollo de la organización campesina en particular y del movimiento popular en general. Por una parte tenemos la llegada al gobierno del partido ARENA y el impulso de su programa de estabilización y ajuste estructural como componentes económicos de su modelo neoliberal. Un segundo evento es la ofensiva militar del FMLN sobre San Salvador y otras ciudades importantes del país. Olro suceso de gran trascendencia es la creación de la Alianza Democrática Campesina (ADC) y su lucha en contra de las políticas agrarias del gobierno. Por último cabe destacar la firma de los acuerdos de paz y su incidencia en la transferencia de tierras y la resolución de la problemática agraria.

\subsection{La estrategia agraria del gobierno de ARENA}

El ascenso del partido ARENA al gobierno en junio de 1989 marca en el área económica, el comienzo de la aplicación de pollticas de estabilización y ajuste estructural propias del modelo neoliberal. En julio del mismo año el primer paquete de medidas es aplicado. Estas medidas afectaron drásticamente las condiciones ya precarias de los sectores populares. Las medidas de liberalización del tipo de cambio, la privatización de los activos del Estado como es el caso de la banca, el aumento de las tarifas de los servicios públicos, etc., se comenzaron ha aplicar sin considerar las condiciones precarias en las cuales se debatia la mayorla de la población. La respuesta del movimiento popular no se hizo esperar. La UNTS, la UNOC y otras organizaciones laborales rechazaron eslas medidas considerándolas que solo beneficiaban a las grandes empresas y perjudicaban cada vez más a las mayorías populares.

El diseño de la politica agraria del gobiemo era consistente con las polf́ticas económicas de estabilización y ajuste. En esta perspectiva se comienza la aplicación de medidas tendientes a eliminar o disminuir las distorsiones macroeconómicas, las cuales se consideraban como generadoras de un sesgo antiagricola especialmente en los precios de los productos agropecuarios, los cuales desfavorecian al productor y conduclan a ineficiencias en la asignación de los recursos económicos 
entre productos ${ }^{57}$. El otro eje fundamental de su politica agraria era la reestructuración de la reforma agraria, la cual se calificaba como una de las causas del estancamiento de la agricultura y que ésta no habla provocado mayores beneficios a los sectores campesinos. En este campo la politica contra la reforma agraria se basó lundamentalmente en la parcelación de las tierras de las cooperativas del sector reformado, promoviendo la pequeña propiedad individual como mecanismo para reactivar este sector. Al mismo tiempo se aplicaron otras medidas tendientes a modificar el papel del Estado en la agricultura, a través de la privatización de la infraestructura de almacenamiento de granos básicos y la eliminación de las actividades del Instituto Regulador de Abastecimiento (IRA). Otras medidas importantes de su politica agraria consistian en la privatización del comercio interno y externo del café y el azúcar, por la vía de la liberalización de la comercialización de estos productos, provocando asi que el Instituto Nacional del Café (INCAFE) y el Instituto Nacional del Azúcar (INAZUCAR) no tuvieran ya incidencia monopólica en estas actividades. Por último es de considerar la privatización de la banca como otra de las medidas tendientes a revertir la lógica de las reformas aplicadas a principios de los ochenta.

La campaña impulsada por el gobierno en contra de la reforma agraria y especialmente contra el sector cooperativo, fue muy intensa tratando de demostrar la ineficiencia de las formas cooperativas y colectivas en la producción agrícola. Asimismo se consideraba muy peligroso el desarrollo de las organizaciones campesinas que se fortalecieron en torno al sector relormado, por lo que habla que desarticularlas. En esta perspectiva la parcelación de las tierras de las cooperativas se constituian en un mecanismo idóneo. Para desarrollar esta política el gobierno aplicó tres leyes, la primera que traslada el control de las propiedades de las cooperativas al ISTA; la segunda es la ley del dominio de las tierras comprendidas en la reforma agraria, la cual facilitará la parcelación de las tierras, y, la tercera ley que crea el Banco de Tierras, haciendo de mercado de tierras el mecanismo único de acceso a la tierra.

Para apreciar la preocupación existente tanto en el gobierno de ARENA, asi como de la AID en cuanto a las reformas impulsadas a principios de los ochenta y especificamente de la reforma agraria, cabe citar a Herman Rosa, que en su trabajo sobre el papel de AID en EI Salvador señala que: en 1989, Bastian Schouten, ex-director adjunto de la Misión de AID en EI Salvador, expresaba incluso que las reformas hablan sido un fracaso, pues si bien "temporalmente quizá habla controlado la insurgencia, habla dejado problemas estructurales que políticamente era difícil de corregir". Según Schouten, las reformas ha- 
blan tenido un impacto adverso en la productividad de la economia, probablemente no hablan llevado a un mayor bienestar de la población salvadoreña, en general, hablan debilitado la credibilidad y los ingresos del gobierno, y probablemente eran (entonces) ya un activo de los insurgentes". Por lo tanto, era prioritario reformar las reformas siendo metas importantes" la privatización de las cooperativas de la fase I, la comercialización privada del café y la apertura del sector financiero a instiluciones privadas ${ }^{58}$.

En general estas medidas orientadas fundamentalmente a lortalecer al sector privado empresarial, debilitar la capacidad de intervención del Estado en la economia y desarticular la respuesta del movimiento popular, generaron un gran descontento en las organizaciones sociales y especialmente en el movimiento campesino. Ante este nuevo escenario las organizaciones campesinas buscaron su unidad para enfrentar las políticas del gobierno y las medidas tendientes ha hacer retroceder la reforma agraria.

\subsection{La Creación de la Alianza Democrática Campesina (ADC)}

Durante 1989 las distintas organizaciones laborales y campesinas se hablan pronunciado en contra de las medidas del gobierno y de los mecanismos de represión que aplicaba. Todos estos movimientos se orientaban a intimidar y desarticular la respuesta del movimiento popular. Los primeros meses de gobierno de ARENA, significaron un recrudecimiento de la violencia y la represión en contra del movimiento popular. Es asl que se desarrollan atentados y cateos a las oficinas de organizaciones laborales y de desarrollo social, se denunciaron numerosas capturas, se perpetra un atentado dinamitero en contra de las oficinas de FENASTRAS, la cual provocó la muerte de diez dirigentes de esta organización y de la UNTS. En general, el panorama político sigue mostrando la cruel dinámica del irrespeto a los derechos humanos.

La ofensiva militar del FMLN en noviembre de 1989 había generado nuevas condiciones para la negociación, pern durante los meses que se impuso el Estado de Sitio, las organizaciones populares y sus dirigentes bajaron el pertil de sus actividades. No es sino hasta marzo de 1990 que nuevamente el movimiento popular sale a las calles y organiza actividades en contra de la política del gobierno e insta a este a que busque una solución política negociada al conflicto. El Comité Permanente del Debate Nacional (CPDN) es la primera organización que se manifestará abiertamente. Esta instancia social que aglutina alrededor de $\mathbf{8 0}$ organizaciones de distinto tipo entre ellas, campesinas, comunidades urbanas, 
universidades, sindicatos, maestros, empleados públicos, comunidades de base de la iglesia, y otros sectores sociales, fue creada en 1988 con el objeto de representar a una gran cantidad de sectores interesados en la búsqueda de una solución negociada al conflicto, la democratización y el respeto a los derechos humanos en El Salvador.

Para marzo de este mismo año los esfuerzos de unidad del movimiento campesino se harlan realidad, creándose la Alianza Democrática Campesina (ADC) que reune a 23 organizaciones campesinas de distinto tipo, entre ellas organizaciones cooperativas de la reforma agraria $y$ del sector tradicional, organizaciones de campesinos sin tierras, asociaciones de pequeños productores, etc. Muchas de estas organizaciones pertenecen a la UNTS y la UNOC.

La ADC en su Segundo Foro realizado el 6 de marzo de 1990, conmemorando el décimo aniversario de la reforma agraria, crítica las políticas agrarias del gobiemo, especialmente las referidas a la reforma agraria y establece una plataforma reivindicativa, la cual contiene aspectos como: Delensa de la tierra de la reforma agraria, mayor acceso a la tierra, otorgar créditos preferenciales, amplios y oportunos, precios juslos a la producción, condonación de la deuda agraria y bancaria, investigación y transferencia de tecnología para cooperativas y pequeños agricultores. Entre otros aspectos también señalan: desarrollo de servicios básicos, sindicalización campesina, cese a las violaciones de los derechos humanos, otros vinculados al cumplimiento de la transferencia de tierras excedentes de las 245 hecláreas, el respeto a la autonomía y autogestión de las cooperativas, llamado al gobierno para buscar una solución negociada al conflicto y otros ${ }^{50}$. (Ver cuadro 4).

La conformación de la ADC es muy importante en esta etapa pues fortalece la capacidad del movimiento campesino en el marco de sus reivindicaciones y en las posibilidades de avanzar hacia mayores niveles de desarrollo económico y social.

Para principios de 1991, la respuesta campesina a la política de lierras del gobierno orientada a bloquear los mecanismos de acceso a esta, asl como a parcelar las propiedades de las cooperativas, provocó el inicio de un proceso sistemático de tomas de tierras las cuales estaban abandonadas, subutilizadas y algunos casos embargadas por la banca comercial. Alrededor de 48 propiedades fueron ocupadas por los campesinos entre marzo y julio de este año. Estas acciones estaban orientadas a resolver el problema del acceso a la tierra a todavía más de 210 familias que no la poseian y la cual era una de las reivindicaciones fundamentales del movimiento campesino. Ciertamente las tomas de tierras en El Salvador no eran un fenómeno nuevo. En la década de 
los 70 se hablan presentado varios casos de ocupación de tierras por los campesinos debido a las mismas razones actuales ${ }^{60}$.

Este fenómeno relativamente nuevo desde la perspectiva del gobierno y el empresariado, atentaba contra el derecho a la propiedad privada y generaba un clima de incertidumbre en los propietarios y productores, por lo que era necesario resolverlo. Algunas propiedades ocupadas fueron desarrolladas por el ejército, pero en otros casos se volvian a ocupar. Al final un acuerdo entre la Fuerza Armada, el Ministerio de Agricultura y Ganaderla y la Alianza Democrática Campesina (ADC), puso fin a las tomas de tierras. Esta nueva dinámica adoptada por el movimiento campesino no hubiera sido posible sin la unidad de todas las organizaciones del campo.

El 6 de marzo de 1992, las organizaciones campesinas de la ADC se pronunciaron sobre la problemática de la tierra, esto se asociaba a su vez con los resultados que los acuerdos de paz, habían dado en el tema de tierras y la problemática agraria. Las posibilidades de transferencias de tierras se hacla más real, habla que evidenciar la política negativa de tierras del gobierno y mostrar donde estaban las tierras susceptibles a ser transleridas a los campesinos. El comunicado señalaba que hablan tierras excedentes de las 245 hectáreas que deberian ser expropiadas por ley y transferidas a los campesinos, existían por lo menos $12 \mathrm{mil}$ hectáreas de tierras ofertadas que el Banco de tierras no habla sido capaz de translerir; que hablan propiedades embargadas por la banca y las propiedades ocupadas el año anterior sobre las cuales habia un acuerdo. En definitiva se trataba de mostrar la incapacidad del gobierno de resolver el problema del acceso a la tierra y la necesidad de establecer nuevos mecanismos para resolver la problemática agraria ${ }^{B 1}$.

En general los acuerdos de paz, en el tema "problema agrario", consideraba la translerencia de lierras para los tenedores y los excombatientes podían andar entre 122.5 mil y 165.9 mil hectáreas, las cuales sumadas a otras tierras que se deberian transferir, más las tierras de la reforma agraria y de otras cooperativas tradicionales, bien podian constituir cerca de la tercera parte de la tierra agricola de país, lo cual era importante para impulsar un proyecto de nuevo tipo en el agro. En esto se centró la discusión durante el último año.

Los acuerdos de paz en el tema económico y social, y especificamente en el problema agrario, se constituyeron en un aspecto fundamental de la lucha del movimiento campesino durante el último año. Ciertamente el acuerdo incluye: la solución a los problemas de las tierras excedentes de las $\mathbf{2 4 5}$ hectáreas, las tierras propiedad del Estado, las tierras ofrecidas en venta al Estado, los beneliciarios de las 
tierras transferidas, el pago de la tierra, la nueva legislación agraria, las tierras dentro de las zonas conflictivas, las tierras ocupadas las cuales estaban bajo acuerdo del 3 de julio, el crédito agricola, la participación de los sectores destinatarios del crédito en las instancias financieras del gobierno, la asistencia técnica y la cooperación internacional para el sector agrlcola. Muchos de estos puntos hablan sido propuestos por las organizaciones campesinas a la mesa de negociaciones entre el Gobierno y el FMLN"2.

Un nuevo tipo de organizaciones campesinas se integrarlan a la ADC. Se trata de las comunidades de repobladores, refugiados, desplazados y otros, que están asentadas en propiedades ubicadas en las zonas ex-conflictivas. Ellas hablan sobrevivido y desarrollado en el contexto de la crisis y la guerra demostrando su capacidad de enfrentar las situaciones más adversas. Esto fortalecería más la unidad y capacidad del movimiento campesino en El Salvador.

Los retos del movimiento campesino en El Salvador, van ahora más allá de la problemática de la tierra. La nueva lucha también persigue desarrollar los mecanismos de comercialización de sus productos, de transformarlos, de establecer estructura de financiamiento, la necesidad de producir para exportar, la de desarrollar su capacidad de autogestión, la de establecer las formas de organización de la producción más efectivas y eficientes para el desarrollo económico y social del país y de la población. En general son nuevos retos que debe asumir el movimiento campesino para transformar la economía y la sociedad y eliminar las causas que dieron origen a la crisis y la guerra.

\section{Conclusiones}

El desarrollo del movimiento campesino en El Salvador en los últimos 25 años es de una trascendencia fundamental, ya que este ha sido un agente fundamental de transformación de la realidad agraria y nacional. Los hechos actuales lo confirman. El agro ha sido históricamente en el país el área de mayor conflictividad social y política. La guerra tuvo como escenario fundamental el mundo rural.

Debemos comprender que el movimiento campesino se debe estudiar también en relación a su articulación con otras fuerzas sociales, en su lucha por entrentar las condiciones adversas que las politicas económicas, los gobiernos y los militares impusieron, además de otros factores que incidlan negativamente en su desarrollo. El proceso político salvadoreño llevó a las organizaciones campesinas y a otras representativas de otros sectores populares, a buscar formas de unidad que 
permitiera enfrentar en mejor forma la lucha por sus intereses y el de una nueva nación.

En los últimos años la unidad del movimiento campesino ha sido importante para frenar un conjunto de politicas que afectan su desarrollo, pero al mismo tiempo su lucha ha sido por generar espacios de negociación con el gobierno y los sectores empresariales, a fin de establecer políticas y transformaciones importantes en el agro, que permitan lograr la estabilidad social y económica necesarios al desarrollo y a la conformación de una nueva economla y sociedad.

\section{Notas}

1. Ver Aguila Pocasangre, Margarita y otros "La Sindicalización Campesina". Tesis presentada para optar al grado de Licenciado en Clencias Jurídicas, Universidad Centroamericana "José Simeón Cañas", San Salvador, marzo de 1990, pp. 55.

2. Ibidem, pp. 55.

3. Ver Cabarnis, Carlos R. "El Salvador. De Movimiento Campesino a Revolución Popular". Tomado del libro de Pablo González Casanova (coordinador), "Historia Política de los Campesinos Latinoamericanos", VOL. 2, Insthuto de Investigaciones Sociales de la U.N.A.M., siglo XXI editores, 1ra. ed., 1985, México, pp. 82.

4. Esta interprelación se fundamenta en la lectura del comunicado oficial "FECCAS-UTC a los cristianos de El Salvador y Centroamericana", el cual aparece en el libro "Iglesia de los Pobres y Organizaciones Populares", UCA Editores, colección La Iglesia en América Latina, 1ra. edición, San Salvador. Centroamérica, 1978, pp. 67-69.

5. Así se autocomprendió la Iglesia y su misión a partir del Conclio Vatleano II y tras la reunión de Medellín en 1968, lo cual se ha dado en llamar la Teología de la Liberación.

6. Ver Aguila Pocasangre, Margarita, op. cit., pp. 112.

7. Ver Campos, Tomás A. "Comentarios a la Carta Pastoral", tomado del libro "Iglesia de los Pobres y Organizaciones Populares", op. cit., pp. 191.

8. Ver comunicado "FECCAS-UTC...", cp. cit., pp. 67.

9. Eslo es lo que Monseñor Oscar A. Romero, Arzobispo de San Salvador, y Monseñor Arluro Rivera Damas, Obispo de Santiago de Marla, plantean en su Tercera y Primera Carta Pastoral, respectivamente. A esta siluación la definen como la violencia represiva del Estado. Ver el libro "Iglesia de los Pobres y Organizaciones Populares", op. cil., pp. 34. 
10. Ver el Editorial "La Cuestión de las Masas", Revista universidad Centroamericana "José Simeón Cañas", N 465 año XIII, julio de 1987, San Salvador, pp. 413-419.

11. Estas otras siete organizaciones populares eran las siguientes:
a) Universitario Revolucionario "19 de julio" (UR-19)
b) Asociación Nacional de Educadores Salvadoreños (ANDES)
c) Unión de Pobladores de Tugurios (UPT)
d) Comité Coordinador de Sindicatos "José Guillermo Rivas"
e) Movimienlo Estudiantil Revolucionario de Secundaria (MERS)
f) Fuerzas Universilarias Revolucionarias (FUR-30)
g) Asociación de Educadores Universitarios (AEU)

12. Esła categoría de análisis político es utilizada por Béjar, Ratael Guido en su artículo "El Movimiento Sindical después de la Segunda Guerra Mundial en El Salvador", revisla ECA, Universidad Centroamericana “José Simeón Cañas", año XLV, № 504, octubre de 1990, pp. 876.

13. Esta es una aplicación directa de la categoría de análisis polílico mencionada en la nota $N^{2} 11$.

14. Comunicado "FECCAS-UTC...", op. cit. pp. 69.

15. Ver Campos, Tomás "El papel de las organizaciones populares en la actual situación del pais", Revista ECA, año XXXIV. N 372-373, octubre-noviembre de 1979, pp. 924-946.

16. Ver Cabarrús, Carlos R., op. cit., pp. 106.

17. Ver Montes, Segundo "Los límites y las posibilidades que enfrenta la participación política en el campo salvadoreño", Revista ECA, Universidad Centroamericana "José Simeón Cañas", año XLII, N 463-464, junio de 1987, pp. 309-310.

18. EI FAPU se componia de las siguientes organizaciones:
a) Movimiento Revolucionario Campesino (MRC)
b) Vanguardia Proletaria (VP)
c) Unión Nacional de Jornaleros (UNJ)
d) Organización Magisterial Revolucionaria (OMA)
e) Asociación Revolucionaria de Estudiantes de Secundaria (ARDES).
1) Frente Estudiantil Revolucionaria "Salvador Allende" (FERSA).

19. Las LP-28 estaban integradas por:
a) Ligas Populares Campesinas
b) Ligas Populares Universitarias
c) Ligas Populares Obreras de Esludiantes de Secundaria. 
20. Ver comunicado "Nuestras Organizaciones Populares en Marcha hacia la Unidad. Posición del FAPU, LP-28, BPA, UDN". Tomado de la Revista ECA, Universidad Centroamericana "José Simeón Cañas", año XXXV, No 375-376, enero-febrero de 1980, pp. 129.

21. Ver Campos, Tomás R. "El Papel..." op. cil., pp. 924.

22. Ver González, Gabriel A. "Genocidio y Guerra de Exterminio en El Salvador", Revista ECA, N 384-385, octubre-noviembre de 1980, año XXXV, pp. 983-989.

23. Esle decreto fue dado el 5 de marzo de 1980 y afectaba aquellas propiedades cuya exlensión excediera las 100 y 150 hectáreas, según fuere el lipo y calidad de suelo.

24. Este decreto fue sancionado el 28 de abril de 1980.

25. Estas cifras fueron obtenidas del Bolet/n "PROCESO", Resumen Semanal Inlormativo del Centro de Documentación e Inlormación, Universidad Centroamericana "José Simeón Cañas", Año 1, $N^{\circledR}$ s 1, 2, 3, 4, 5, 6, 7, 8, 9, 10, $11,12,13,14,17,18$ y 19.

26. Ver Editorial "La Cueslión..." op. cit. pp. 430.

27. Ver Garcla, Juan José. Las Fuerzas Laborales ante el Nuevo Proyecto Norteamericano". Revisla ECA, año XXXVIII, N 415-416, mayo-junio de 1983, San Salvador, pp. 501-506.

28. Ver comunicado "Declaración de Principios y Objetivos de la Unidad Popular Democrática (U.P.D.)", Diario El Mundo, 25 de septiembre de 1980, San Salvador.

29. Para mayores detalles consultar Montes, Segundo "El Agro Salvadoreño (1973-1980)", Universidad Centroamericana "José Simeón Cañas", año XLI, No 449, marzo de 1986, pp. 205-229.

30. Para mayores detalles ver el articulo de Casper, Norman "EI IADSL y la Corrupción del Movimiento Sindical en El Salvador", revista ECA, Universidad "José Simeón Cañas", año XLI, No 449, marzo de 1986, pp. 205-229.

31. "Sectores Aclivos no Beligerantes en El Salvador", de autor anónimo, el cual apareció en la revista ECA, año XXXIX, № 425, enero de 1984, Pp. 153.

32. Ver "Comunicado de la UPD al pueblo salvadoreño", El Diario de Hoy, miércoles 31 de diciembre de 1980, San Salvador.

33. Datos tomados de la Revista ECA, año XXXVI, junio de 1981, San Salvador, pp. 621.

34. Ver los comunicados "La UPD se solidariza" y "Mensaje de la UPD al pueblo salvadoreño y a los trabajadores del mundo", publlcados respectivamente en el Diario El Mundo del 1/5/81 y en El Diario de Hoy del $4 / 9 / 81$. 
35. Ver el comunicado "La Unidad Popular Democrática frente a las elecciones", lomado de la sección de documentación de la revista ECA, Universidad Centroamericana "José Simeón Cañas", año XXXVII, No 399400, enero-lebrero de 1982, pp. 135-36.

36. Ver el comunicado de la U.P.D. “Análisis del año 1982 y perspectivas para el año 1983" El Diario de Hoy, sábado 5 de lebrero de 1983.

37. Ver Garcia, Juan José “La Fuerzas...”, op. cil., pp. 503-504.

38. Ver Casper, Norman "El IADSI..." op. cit., pp. 208.

39. Ver e comunicado "Declaración de San José, Comité Político de la UPD", tomado de la revista ECA, año XXXVIII, N N 415-416, mayo-junio de 1983, pp. 581-82.

40. Ver el comunicado "PDC-UPD en el pacto social", tomado de la revista ECA, año XXXIX, № 426-427, abril-mayo de 1984, San Salvador, pp. 349.

41. Ver el comentario "La UPD y el Pacto Social", Revista ECA, año XXXIX, N” 434, diciembre de 1984, San Salvador, pp. 466.

42. Ver el comunicado "Carta abierta de la U.P.D. al presidente de la república", tomado de la Revista ECA, año XL, № 439-440, mayo-junio de 1985, San Salvador, pp. 466.

43. Para mayores delalles consultar el Informativo semanal "El Salvador PROCESO", publicado por la Universidad Centroamericana "José Simeón Cañas", año 6, N² 224, 10 de lebrero de 1986.

44. Esta cifra del número de atiliados se extrajo del Boletln semanal "El Salvador PROCESO", año 6 N²26, 24 de febrero de 1986.

45. Ibjdem.

45. Ibidem.

47. Ver el documento "Planteamiento de la UNTS". Informativo Semanal "EI Salvador PROCESO", año 6, N²226, 24 de febrero de 1986.

48. Ver el comunicado "La UNTS ante la reunión de Presidentes de Centroamérica en Esquipulas", tomado de la revista ECA, año XLI, N 40. 451/452, mayo-junio de 1986, San Salvador, pp. 508-510.

49. Ver Casper, Norman "El IADSL..." op. cit. pp. 319.

50. Ibidem, pp. 223.

51. Ver el artículo "La UNOC: intento del PDC de recomponer su base social", boletín semanal "El Salvador, PROCESO", año 6, N" 228, 10 de marzo de 1986.

52. Ver comunicado "La UNOC a los compañeros Irabajadores salvadoreños, en el dla inlemacional del trabajon", tomado de la revista ECA, año XLII, $\mathrm{N}^{\circ}$ 463-464, mayo-junio de 1987, pp. 377-79. 
53. Ver comunicado "UNTS: Balance sobre los tres años del gobiemo de Duarte", tomado de la Pevista ECA, año XLII, No. 463/464, mayo-Junio de 1987, pp. 388.

54. Ver comunicado "UPD manifiesto", tomado de la revista ECA, año XLI. No 457/458, noviembre-diciembre de 1986, pp. 1078-79.

55. Ver Bélar Rafael Guldo “El Movimiento...", op. cit., pp. 884-85.

56. Ver Martín-Baró, Ignacio "El Salvador 1987, Revista ECA, año XLIII, N 471/472, enero-febrero de 1988, pp. 31.

57. Norton, Roger d. y Llort, Mercedes. Una estralegla para la reactivación del sector agropecuario. Fundación Salvadoreña para el Desarrollo Económlco y Social (FUSADES). Documento de Trabajo N² 6. Octubre de 1989.

58. Rosa, Herman. EI papel de la asistencia de AID en el fortalecimiento de nuevas instituciones del sector privado y en la transformaclón global de la economía salvadoreña: el caso de FUSADES. Ponencia presenlada en el XVII congreso de LASA (Latin American Studies Association). Los Angeles, septiembre 1992.

59. Documento “Diez años de reforma agraria. II Foro de la Alianza Democrálica Campesina (ADC). Publicado en la Revista Estudios Centroamericanos (ECA) N 497 marzo 1990. El Salvador.

60. Hemández R. Pedro Juan. Problema Agrario y Toma de Tierras. (Análisis Preliminar). Revista "El Salvador. Coyuntura Económica". ND 37. Jullo-Agosto 1991. Instituto de Investigaciones Económicas. Unlversidad de EI Salvador.

61. Comunicado de la Alianza Democrática Campesina (ADC). A Doce Años de la Relorma Agraria Urgen Nuevas Soluciones al Problema de la Tlerra. La Prensa Gráfica 6 de marzo de 1992. San Salvador.

62. Acuerdos de Paz entre el Gobiemo de El Salvador y el Frente Farabundo Martl para la Liberación Nacional (FMLN). 15 de enero de 1992. Capltulo V. Tema Económico y Social. 